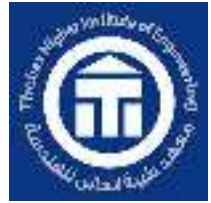

INTERNATIONAL JOURNAL OF ADVANCED ENGINEERING

AND BUSINESS SCIENCES (IJAEBS)

Journal homepage: International Journal of Advanced Engineering and Business Sciences (ekb.eg)

\title{
Optimal Parameters Model Predictive Control for Single Area Load Frequency Control
}

Mohamed. A. Shamseldina, M. A. Abdel Ghany ${ }^{\text {**, }}$, Sherouk Osama Ibrahim

Future University in Egypt, Faculty of Engineering, email: Mohamed.abelbbar@ fue.edu.eg

Department of Electrical Engineering, Faculty of Engineering October 6 University, email: mghany1988@hotmail.com

Department of Electrical Engineering, Faculty of Engineering October 6 University, email: Sho_sunrise@yahoo.com

*Corresponding author: Email address: mghany1988@ hotmail.com

Received: 06-April-2021

Accepted: 06-April-2021

Published: 10-April-2021

\section{ABSTRACT:}

In this paper, a new load frequency control (LFC) using the model predictive control MPC technique is presented. The MPC technique has been designed such that the effect of the uncertainty due to governor and turbine parameters variation and load disturbance is reduced. A simplified frequency response model is introduced, and physical constraints of the governor and turbine are considered in this model. The model was employed in the MPC structure. The optimal parameter values of MPC were obtained using a Genetic Algorithm (GA) based on a certain cost function. The presented MPC is compared against a conventional proportional integral derivative (PID) controller. Simulations show that the MPC gives a better frequency response while using cheaper resources. The simulation results illustrate that MPC could be a realistic solution to some of the LFC problems power systems are facing today. Also, it can absorb and predict the different types of disturbances.

Keywords: Predictive Control; Single Area; Genetic Algorithm; PID. 


\section{INTRODUCTION}

Over the past decades, due to the fact that LFC constitutes an important function of power system operation where the main objective is to regulate the output power of each generator at prescribed levels while keeping the frequency fluctuations within prespecified limits [1].

Many control strategies have been proposed and investigated by several researchers for LFC design of power systems [2]. Robust adaptive control schemes have been developed in [3] to deal with changes in system parameters. Fuzzy logic controllers have been used in many reports for LFC design in a two area power system [4], with and without nonlinearities. The applications of artificial neural network, genetic algorithms, and optimal control to LFC have been reported in [5]. In their findings it is observed that the transient response is oscillatory and it seems some other elegant techniques are needed to achieve a desirable performance. On the other hand, the MPC appears to be an efficient strategy to control many applications in industry, it has many advantages such as very fast response, robustness against load disturbance and parameters uncertainty [6-8].

Its straightforward design procedure is considered as a major advantage of the MPC. Given a model of the system, only an objective function incorporating the control objectives needs to be set up. Additional physical constraints can be easily dealt with by adding them as inequality constraints,

whereas soft constraints can be accounted for in the objective function using large penalties. Moreover,

MPC adapts well to different physical setups and allows for a unified approach $[9,10]$. In this paper, the load frequency control for a single area power system has been developed based on the MPC technique. The MPC parameters were obtained using GA based on a cost function. The technique calculates the optimal control signal while respecting the given constrains over the output frequency deviation and the load change. The effects of the physical constraints such as generation rate constraint (GRC) and speed governor dead band [11,12] are considered. The power system with the proposed MPC technique has been tested through the effect of uncertainties due to governor and turbine parameters variation and load disturbance using computer simulation. A comparison has been made between the MPC and the traditional integral controller confirming the superiority of the proposed MPC technique. The simulation results proved that the proposed controller can be applied successfully to the application of power system load frequency control. 


\section{Power System Modelling}

The model of the LFC of a single area power system controlled by FOPID is shown in Fig. 1 [13]. The states: $x 1, x 2$ and $x 3$ are the change in system frequency, the incremental changes in generator output and the governor valve position, respectively. The control objective in the LFC problem is to keep the change in frequency $(\Delta \mathrm{F}=\mathrm{x} 1)$ as close to zero as possible when the system is subjected to a load disturbance $\Delta \mathrm{Pd}$ by manipulating the controlled input $(\mathrm{u})$. The system parameters are $\mathrm{Kp}=$ plant gain $=120 \mathrm{~Hz} / \mathrm{pu} . \mathrm{MW}, \mathrm{Tp}=$ plant model time constant $=20 \mathrm{sec} . \mathrm{Tt}$ $=$ turbine time constant $=0.3 \mathrm{sec} ., \mathrm{Tg}=$ governor time constant $=0.08 \mathrm{sec} ., \mathrm{R}=$ speed regulation due to governor action $=2.4 \mathrm{~Hz} / \mathrm{pu} . \mathrm{MW}$.

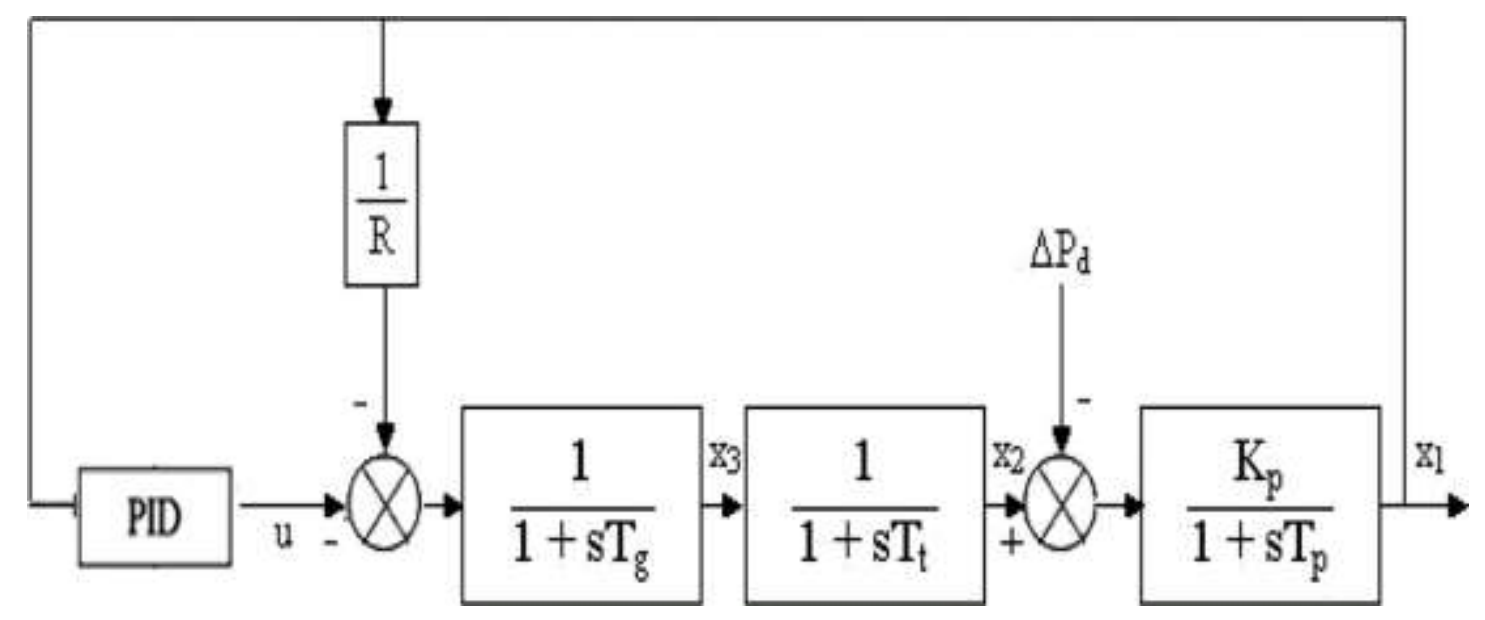

Fig. 1 Block Diagram of single area LFC.

\section{GA-PID Controllers and Fitness Function Criteria}

The controller type used here is a PID controller with the transfer function given in (1):

$$
\mathbf{k}(\mathbf{s})=\mathbf{k}_{\mathbf{p}}+\frac{\mathbf{k}_{\mathbf{i}}}{\mathbf{s}}+\mathbf{k}_{\mathbf{d}} \mathbf{s}
$$

where: $\mathrm{kp}$, ki and kd are proportional, integral and differential gains respectively. The input to the controller is the incremental frequency deviation $\Delta \mathrm{F}$

The function of each part of a PID controller can be described as: the proportional part reduces the error responses of the system to disturbances, the integral part eliminates the steadystate error and finally the derivative part dampens the dynamic response and improves the system stability [13].

\section{GA-based Model Predictive Control}


MPC has attracted notable attention in control of application in industry like electromechanical systems, petrol industry and many other applications. During last decade, MPC was applied for controlling plants with slow dynamics. However, recent studies on MPC applications include plants with fast dynamics such as air plane control. The main advantage that distinguishes MPC from most other control methods is the receding/control horizon $N c$ principle. An MPC controller solves, at each control interval $k$, a finite horizon optimal control problem. Only the first value of the resulting optimal control variable solution is recorded and then applied to the plant, and the rest of the solution is rejected. The same procedure is then repeated at each sampling instant, and the prediction horizon $N p$ is shifted forward one step, as shown in Fig. 2

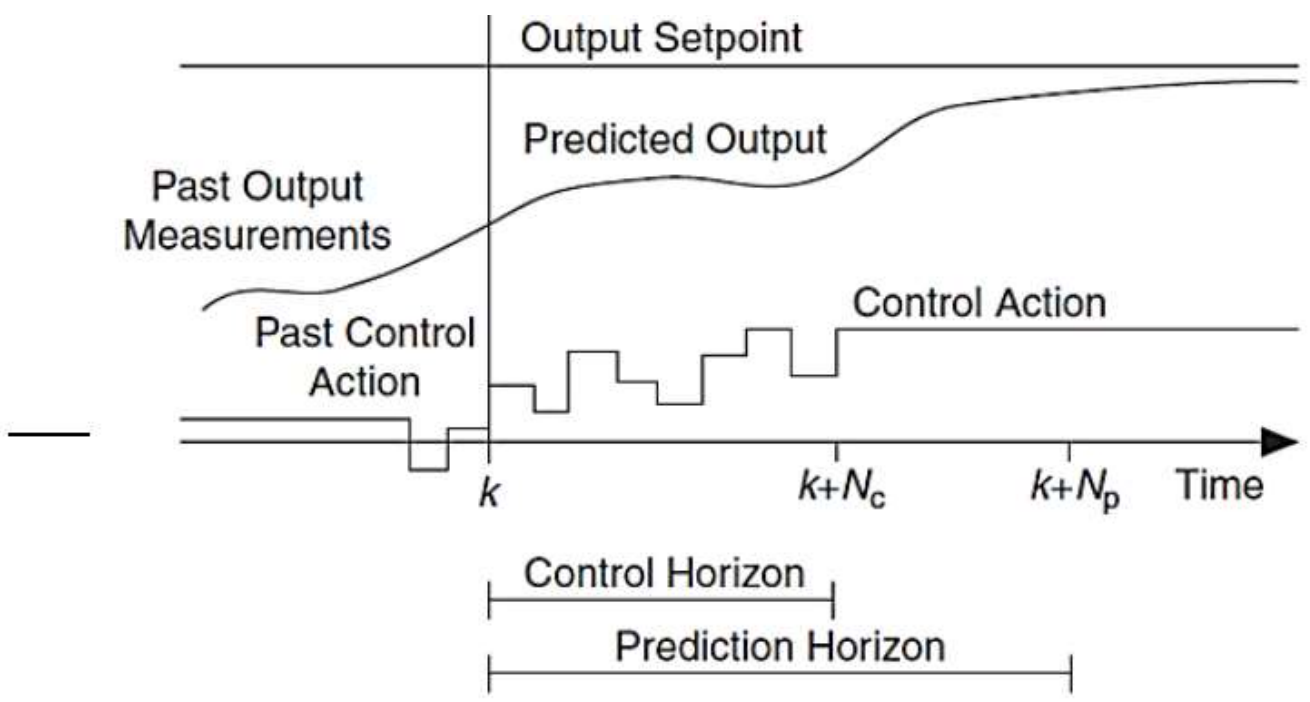

Fig. 2 Principles of the MPC.

MPC theory depends on the explicit use of a prediction model of the system response to obtain the control actions by minimizing an objective function. Optimization objectives include minimization of the error between the predicted and trajectory response, and the control effort is subjected to given constraints, as illustrated in Fig. 3. Minimizing of the objective function based on the desired output trajectory over a prediction horizon with a chosen samples, which can be achieved using an accurate internal model that takes the essential on linearity of the process under control to predict the dynamic performance. 


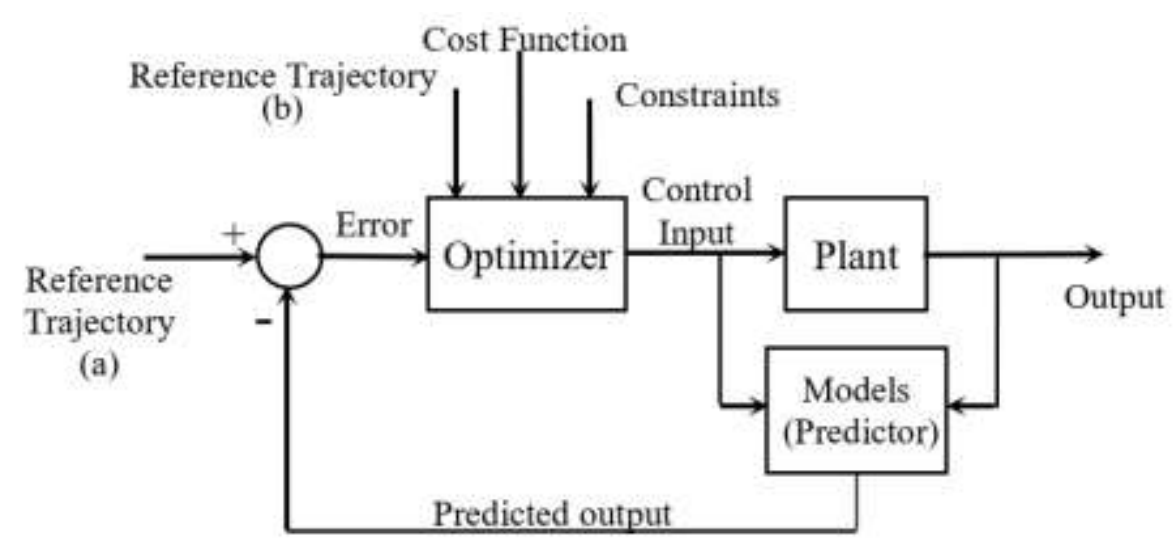

Fig.3. MPC Configuration

The actual closed-loop specification of the system with controller, rise time $\left(t_{r}\right)$, maximum overshoot $\left(M_{p}\right)$, settling time $\left(t_{s}\right)$, and steady state error $\left(e_{S S}\right)$ are used to evaluate the cost function. This is done by summing the errors between actual and specified specification as given by (2).

$$
f=\frac{1}{\left(1-e^{-\beta}\right)\left(M_{p}+e_{s S}\right)+e^{-\beta}\left(t_{s}-t_{r}\right)}
$$

This cost function can satisfy the designer requirement using the weighting factor value $(\beta)$. The factor is set larger than 0.7 to reduce over shoot and steady-state error. If this factor is set smaller than 0.7 the rise time and settling time will be reduced.

The following parameters summarizes the values the GA-MPC parameters obtained from GA optimization.

- Control interval(time units) $=0.005$

- Prediction horizon(intervals) $=30$

- Control horizon(intervals) $=5$

- Input weights MPC controller=0.1

- Output weights subsystem $=1$

- The response with (robust) $=.68$

- The estimation value $=.58$ 


\section{SIMULATION RESULTS}

\subsection{Step disturbance_Pd $=5 \%$ (Case 1$)$}

In order to compare the system driven by GA based Optimum PID (OPID), Model Predictive controller Self-Tuning a relative disturbance $\Delta \mathrm{P}_{\mathrm{d}}$ of $5 \%$ is applied to the single area Load Frequency Control (LFC) system. The time response of the frequency deviation $\Delta \mathrm{F}$ and the control input deviation $\Delta U$ are shown in Fig. 4. It is observed that the damping of the system frequency is improved significantly for all controllers however, the Model Predictive controller responds better than the other two with fewer overshoots and shorter settling time. The control input $\Delta U$ gives similar behavior for the controlled system.

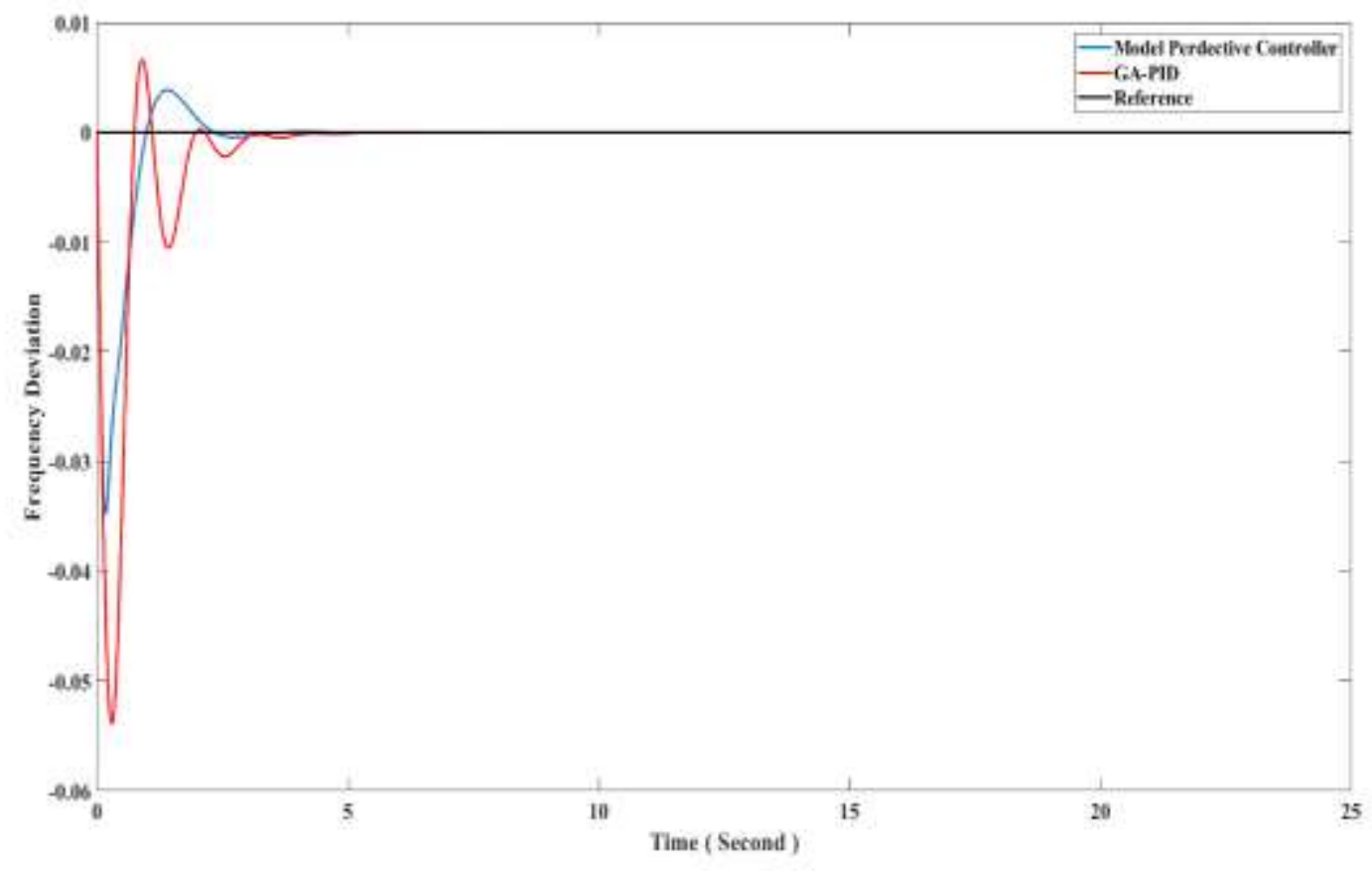

Fig.4. MPC Configuration 


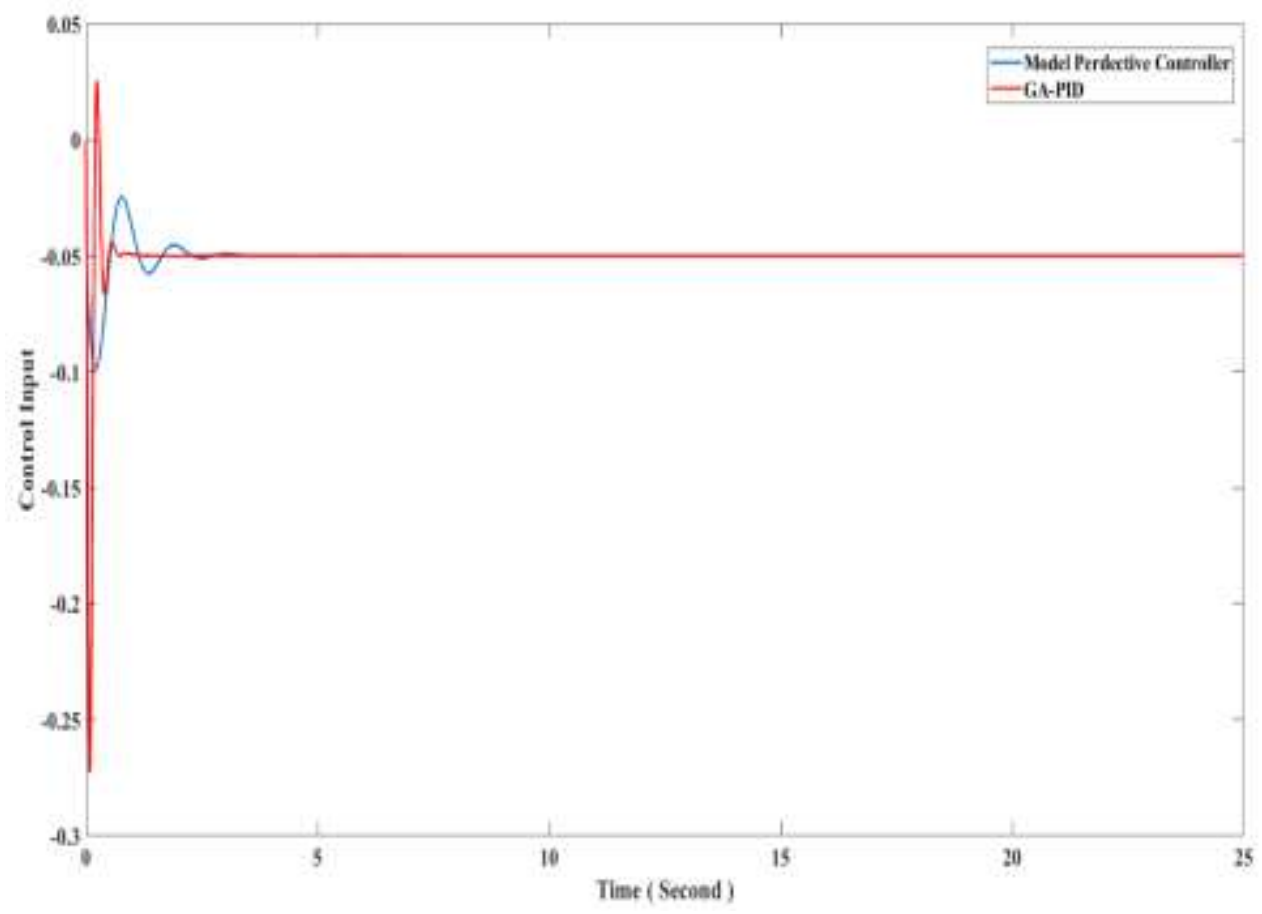

Fig.5. MPC Configuration

\subsection{Tracking disturbance variations (Case 2)}

Figure 6 shows the dynamic response of both $\Delta \mathrm{F}$ and $\Delta \mathrm{U}$ following a variation of $\Delta \mathrm{Pd}$ as seen in Fig. 7 and Fig. 8, it is obvious that the system driven by Model Predictive controller shows better performance with less overshoot and faster response. The control input for the two controllers give satisfactory results.

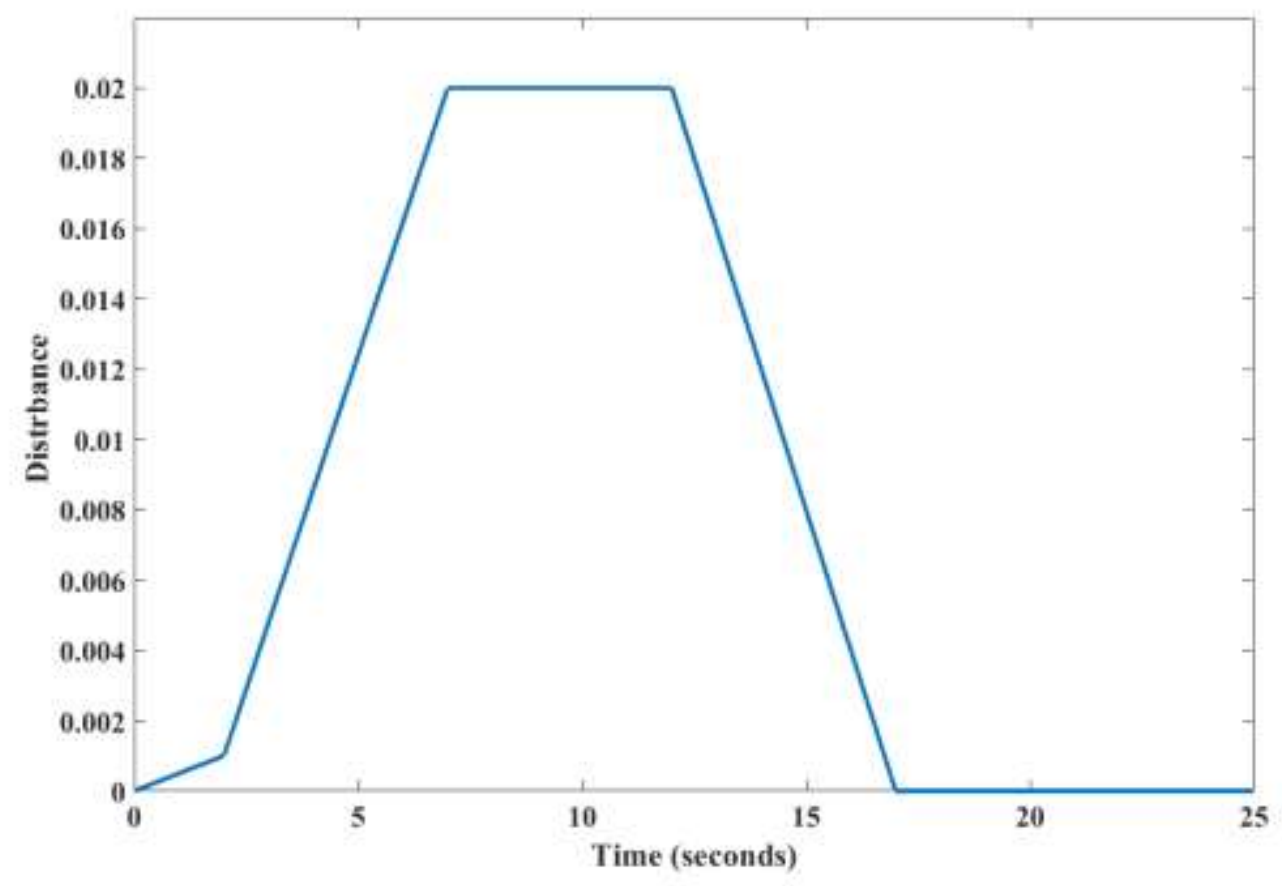

Fig.6. MPC Configuration 


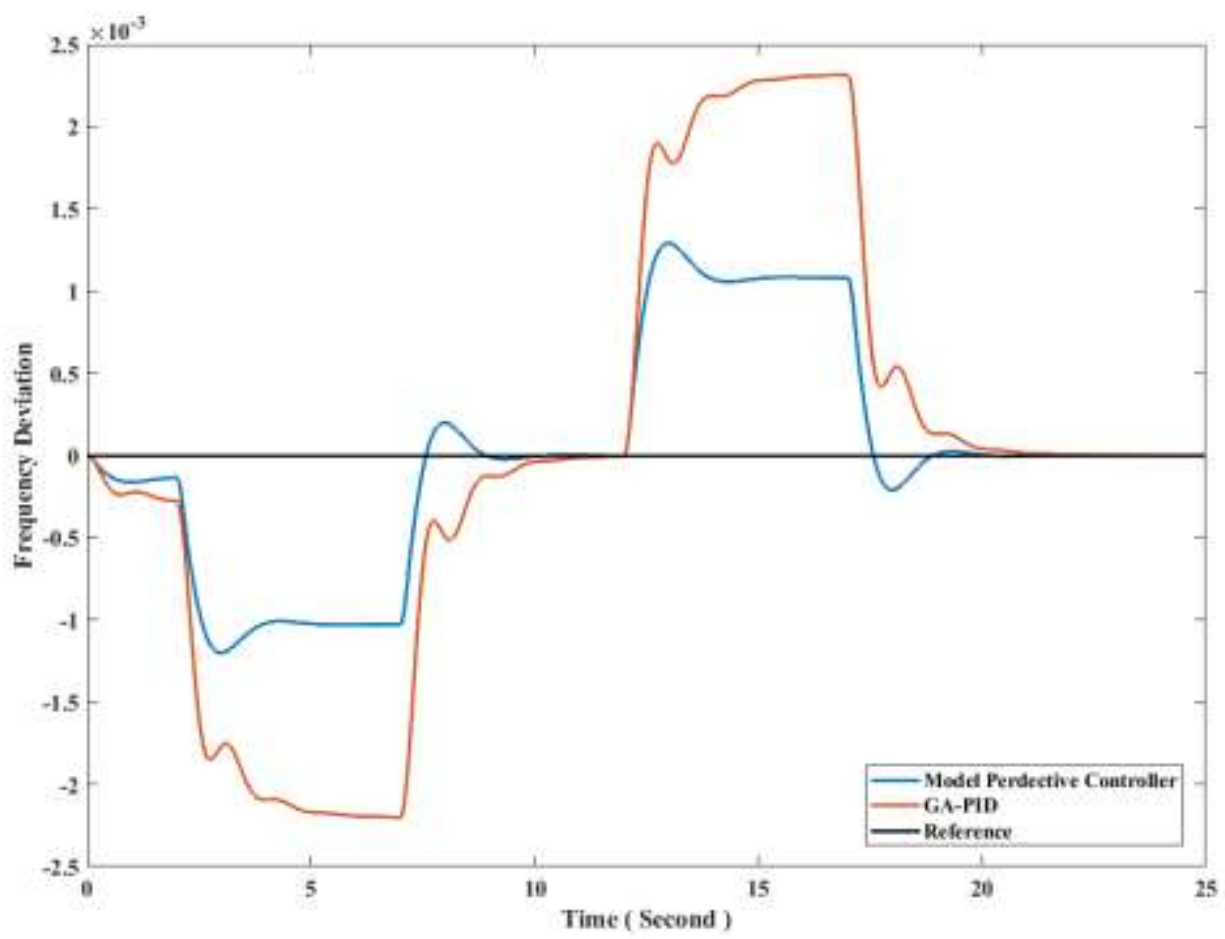

Fig.7. MPC Configuration

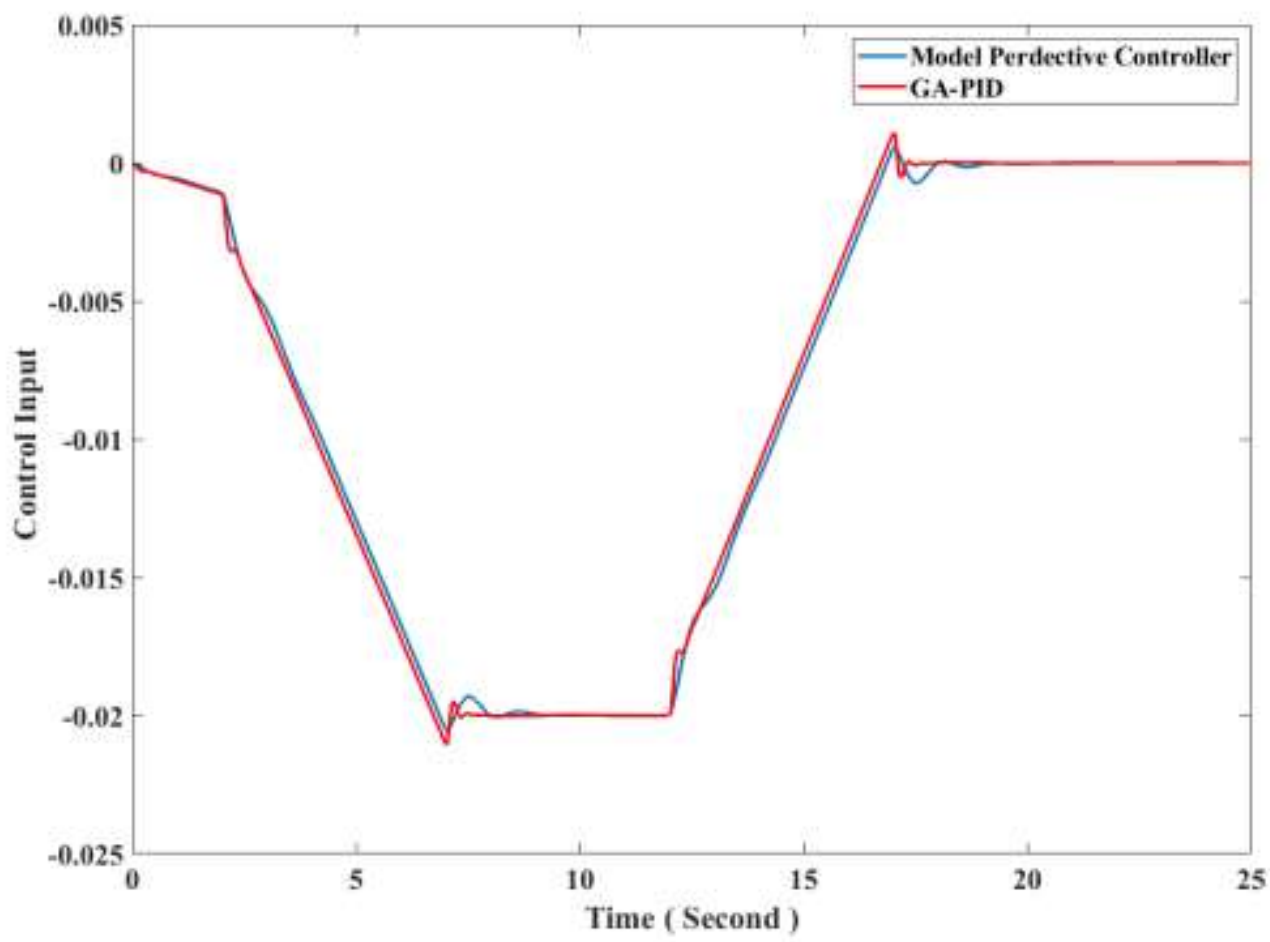

Fig.8. MPC Configuration 


\subsection{Step change in the disturbance $\Delta \mathrm{Pd}$ (Case 3)}

In this case, a step increase in $\Delta \mathrm{Pd}$ by $2 \%$ in $13 \mathrm{~s}$ followed by a step decrease to zero Fig. 9 is applied to the system driven by each of the controllers; Model Predictive controller, and GAPID. The frequency deviation and control input changes are shown in Fig. 10 and Fig.11, respectively. It is clear that the system response with Model Predictive controller shows better rise time, overshoot and settling time characteristics relative to the other two.

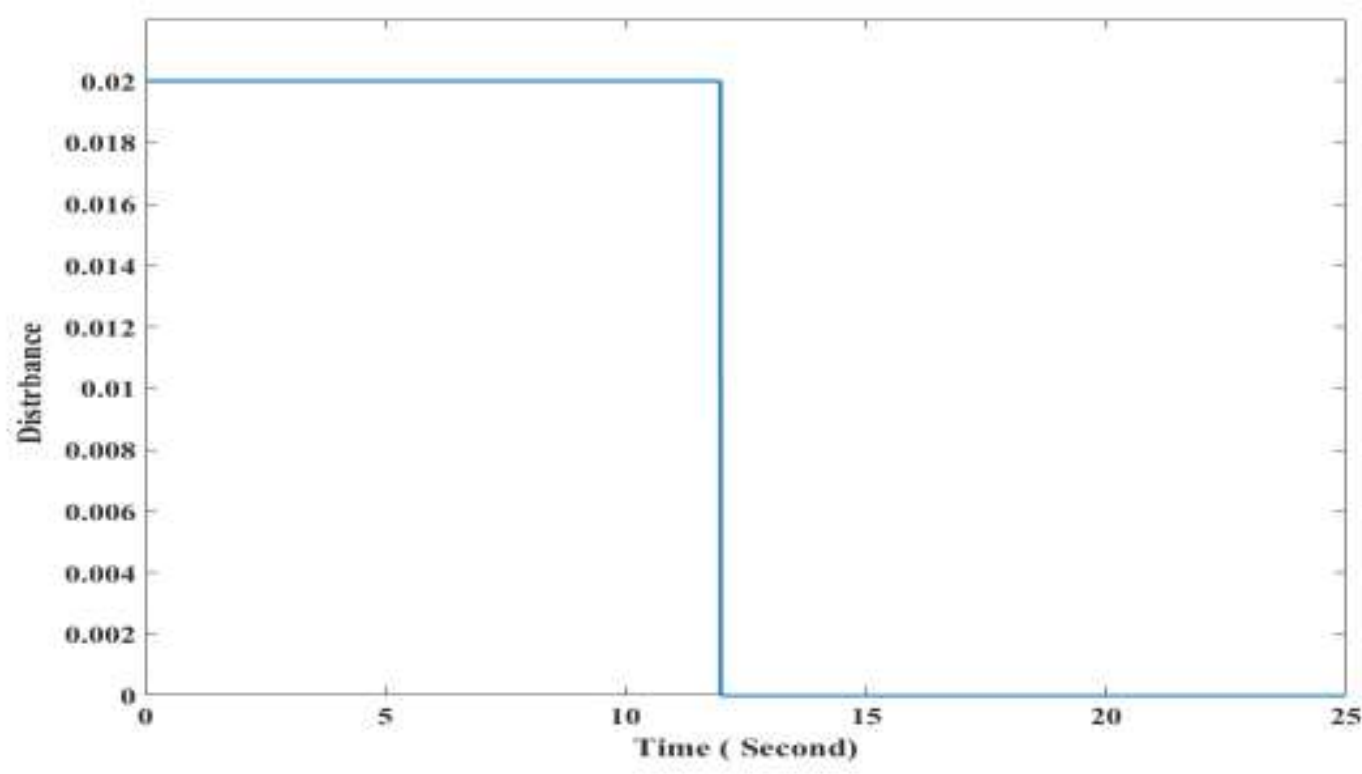

Fig.9. MPC Configuration

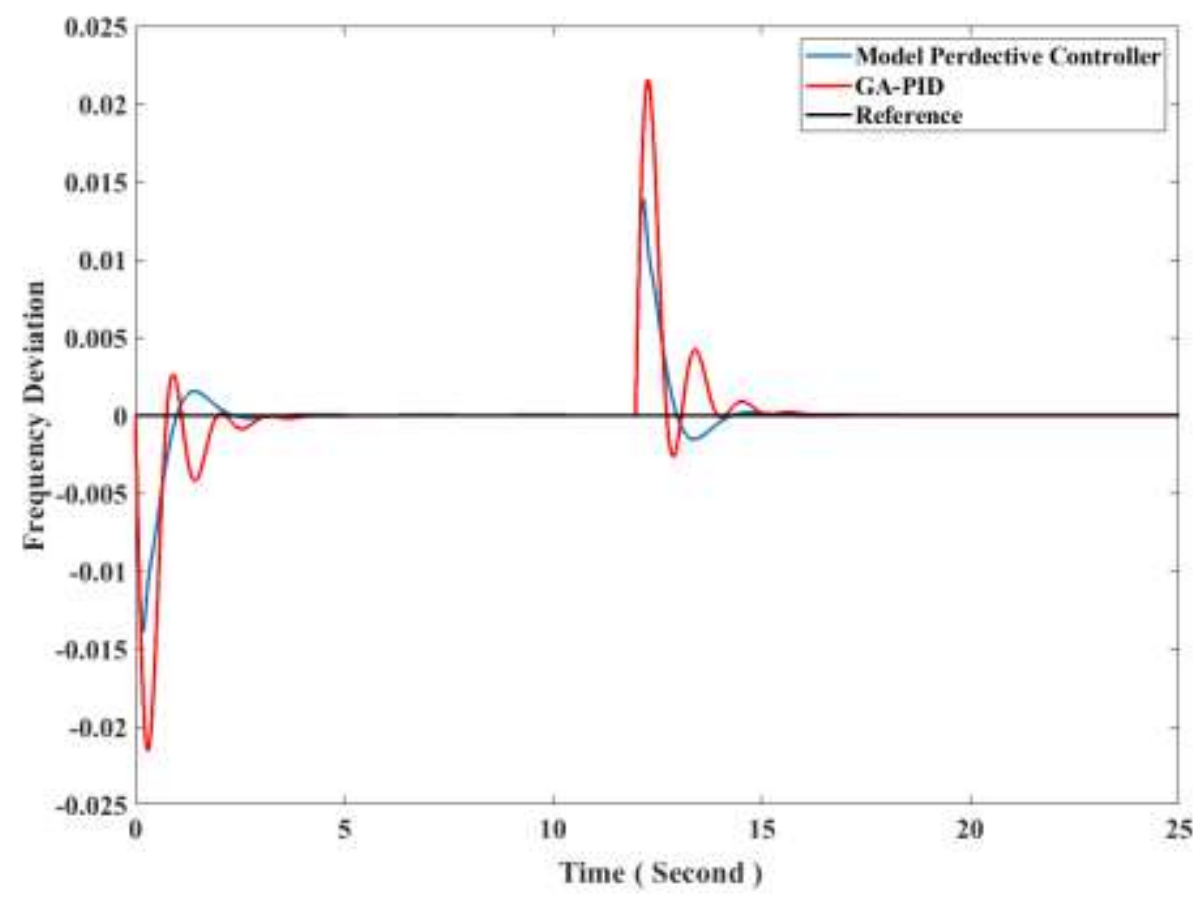

Fig10. MPC Configuration 


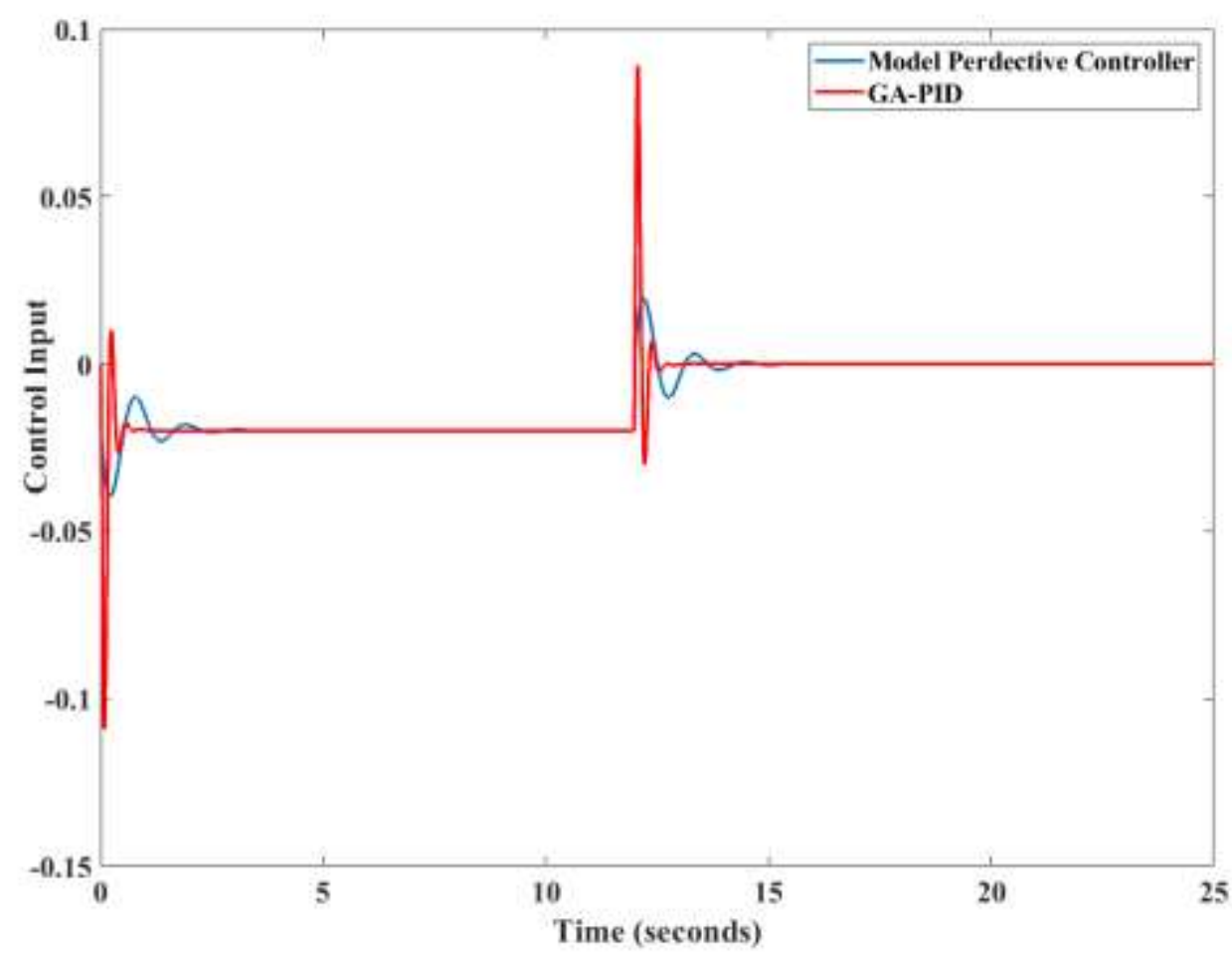

Fig.11. MPC Configuration

\section{CONCLUSION:}

A first-hand load frequency control (LFC) using the model predictive control MPC technique is presented. The MPC technique has been planned such that the effect of the uncertainty due to governor and turbine parameters variation and load disturbance is abridged. A basic frequency response model is introduced, and physical constraints of the governor and turbine are considered in this model. The model was employed in the MPC structure. The optimal parameters values of MPC were obtained using Genetic Algorithm (GA) based on a certain cost function. The presented MPC is compared against a conventional proportional integral derivative (PID) controller. Simulations show that the MPC gives better frequency response compared to other techniques. This paper shows that MPC can solve the LFC problems of power systems. 


\section{REFERENCES}

[1] M.George, "Speed Control of Separately Excited DC Motor," American Journal of Applied Sciences 5 (3): 227-233, 2008.

[2] Wai Phyo Aung, "Analysis on Modeling and Simulink of DC Motor and its Driving System Used for Wheeled Mobile Robot,", PWASET VOLUME 26 DECEMBER 2007 ISSN 1307-6884.

[3] M. Namazov and O. Basturk " DC motor position control using fuzzy proportional-derivative controllers with different defuzzification methods," TJFS: Turkish Journal of Fuzzy Systems (eISSN: 1309-1190), Vol.1, No.1, pp. 36-54, 2010.

[4] V. K. Mehta and R. Mehta, " Principles of Electrical Machines," S. Chand \& Company LTD., Ram Nagar, New Delhi, 2009.

[5] A. J. Mohammed, "Speed Control for Separately Excited DC Motor Drive (SEDM) Based on Adaptive Neuro-Fuzzy Logic Controller," Eng. \& Tech. Journal, Vol.31, No.2, 2013.

[6] V. K. Mehta and R. Mehta, "Principles of Electrical Machines," S. Chand \& Company LTD., Ram Nagar, New Delhi, 2009.

[7] McLean, D., 1978, "Mathematical Models of Electrical Machines," Measurement and Control, Vol. 11, June, pp. 231- 236.

[8] Welch Jr., R.H., "Mechanical Resonance in a Closed Loop Servo System,"Tutorial for Motion Control Expo.

[9] Ogata, K., 1998, "Modern Control Engineering," Prentice-Hall.

[10] Fitzgerald, A.E. and Kingsley, C., 1961, "Electric Machinery: The Dynamics and Statics of Electromechanical Energy Conversion,"McGraw-Hill Book Company.

[11] Sen, P.C., 1989, "Principles of Electric Machines and Power Electronics," John Wiley \& Sons.

[12] E.F. Camacho and C. Bordons, "Model Predictive Control," 1999, Springer.

[13] A. Bensenouci and A. M. Abdel Ghany, "Performance Analysis and Comparative Study of LMIBased Iterative PID Load-Frequency Controllers of a Single-Area Power System", WSEAS (World Scientific and Engineering Academy and Society) on Power Systems Journal, Issue 2, Vol. 5, pp. 85-97 April 2010. 